Journal of Southeast Asian

\title{
The Linguistic Landscape of a Cambodia Town in Lowell, Massachusetts
}

Virak Chan

Purdue University, virakifl@fulbrightmail.org

Follow this and additional works at: https://docs.lib.purdue.edu/jsaaea

Part of the Bilingual, Multilingual, and Multicultural Education Commons, and the Discourse and Text Linguistics Commons

\section{Recommended Citation}

Chan, Virak (2018) "The Linguistic Landscape of a Cambodia Town in Lowell, Massachusetts," Journal of Southeast Asian American Education and Advancement. Vol. 13 : Iss. 1, Article 5.

DOI: $10.7771 / 2153-8999.1137$

Available at: https://docs.lib.purdue.edu/jsaaea/vol13/iss1/5

This document has been made available through Purdue e-Pubs, a service of the Purdue University Libraries. Please contact epubs@purdue.edu for additional information.

This is an Open Access journal. This means that it uses a funding model that does not charge readers or their institutions for access. Readers may freely read, download, copy, distribute, print, search, or link to the full texts of articles. This journal is covered under the CC BY-NC-ND license. 


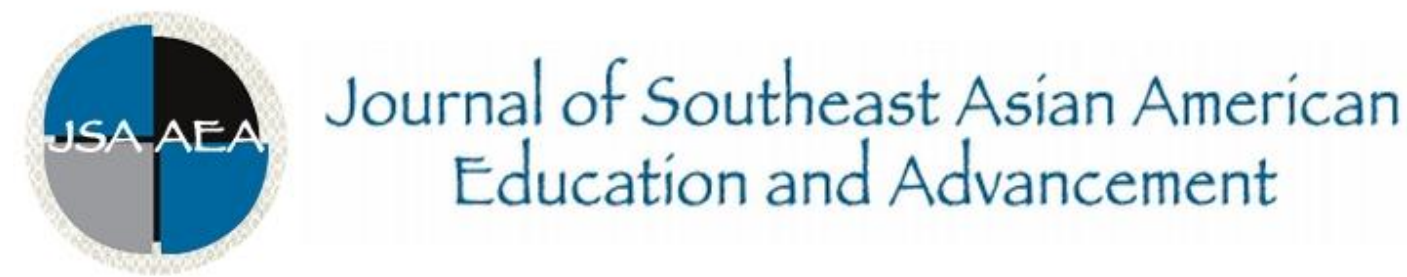

Vol. 13 Iss. 1 (2018)

WwW.JSAAEA.org

\title{
The Linguistic Landscape of a Cambodia Town in Lowell, Massachusetts
}

\author{
Virak Chan \\ Purdue University
}

\begin{abstract}
This research was conducted in a Cambodian community recently recognized as the second Cambodia Town in the United States, which is new to the linguistic landscape research community. Data for this research were 279 photos collected in Lowell, MA during August of 2013. They were collected from two important main streets (Westford Street and Branch Street) that house many Cambodian businesses. The site for this data collection was purposefully selected because it is located in the heart of the Cambodia Town with many Cambodian businesses and offices. All the photos were entered into and coded with NVivo 10. Findings were reported in relation to the number of languages, the role of Khmer language, and the amount of transliteration reflected in the signs. These findings were discussed with implications for a better understanding of the language-in-contact situation (in this case Khmer and English) and the functions of Khmer as a minority language in this context. This understanding also has implications for the learning and teaching of English or Khmer in this community and the language planning of the Cambodia Town.
\end{abstract}

Keywords: Linguistic landscape, Cambodia town, Khmer language

\section{Introduction}

Cambodian Americans are a recent minority group in the United States, many of whom arrived as refugees in the early 1980s. They were survivors of the genocide under the rule of Pol Pot between 1975 and 1979 and had to escape from the social and political instability after the period. Most of them had to stay in refugee camps along the Cambodia-Thai border before they were resettled in the United States through the resettlement programs organized by the U.S. Department of State. According to the 1990 U.S. Census, the largest number of Cambodian Americans was resettled in California with a population close to 70,000 followed by Massachusetts with over 14,000.

Through the resettlement program, many of the Cambodian refugees had to learn English and American culture in preparation for their integration into the United States. However, many of them had problems adjusting to the American culture and this is due largely to the cultural

\footnotetext{
@)

SDRERIIGHISRESERNEDR Readers are free to copy, display, and distribute this article, as long as the work is attributed to the author(s) and the Journal of Southeast Asian American Education \& Advancement, it is distributed for non-commercial purposes only, and no alteration or transformation is made in the work. More details of this Creative Commons license are available at http://creativecommons.org/licenses/by-nc-nd/3.0/. All other uses must be approved by the author(s) or JSAAEA. Journal of Southeast Asian American Education \& Advancement, Vol. 13. Iss. 1. (2018) ISSN: 2153-8999
} 
differences and the lack of proficiency in English language. According to Needham and Quintiliani (2010) this difficulty in adjusting to new language and culture partly contributed to secondary migration and led to the emergence of Cambodian American communities in different parts of the United States such as in Long Beach, California and in Lowell, Massachusetts. Cambodian communities can also be found in towns and cities in other states including Rhode Island, Pennsylvania, the Washington, DC area, Virginia, Georgia, Florida, Illinois, Ohio, Texas, Utah, Arizona, Oregon, and Washington.

With a strong interest in studying the language and cultural maintenance of Cambodian American communities in the United States, I visited Lowell, Massachusetts in the summer of 2013 for the annual Asian Water Festival, and stayed with a Cambodian American host family there. Besides joining the Water Festival with Cambodian American friends in the area, I took photos of the signs in two important streets that housed many Cambodian American businesses, ate at Cambodian American restaurants, and interacted with many of the Cambodian American residents in the area. These activities are the basis for generating data for this project.

\section{Linguistic Landscape Overview}

Linguistic landscape (LL) is an emerging new field of study that interests researchers from a wide range of disciplines including sociolinguists, cultural geographers, applied linguists, sociologists, and psychologists. According to Ben-Rafael, Shohamy, and Barni (2010), linguistic landscape research seeks to understand the symbolic construction of public spaces. These public spaces include "language of public road signs, advertising boards, street names, place names, commercial shop signs, and public signs on government buildings ... of a given territory, region or urban agglomeration" (Landry \& Bourhis, 1997, p. 25).

Commercial zones are popular sites in LL research because of their large number of stores and restaurants which contain more language display than public sector or residential neighborhoods (Leeman \& Modan, 2010). Many recent research articles examined the linguistic landscapes for various purposes in different places, most of which are commercial zones. For instance, Torkington (2009) examines the LL in the Golden Triangle in Algarve, Portugal; Lou (2012) in China Town in Washington, DC; Cenoz and Gorter (2006) in the shopping streets of two bilingual cities (Friesland in the Netherlands and the Basque Country in Spain); and Kasanga (2012) in a commercial neighborhood in Phnom Penh, Cambodia. Many, if not all of the signs which include the display of languages in these areas are usually captured with a camera through a period of time and are used as a main source of data for the research.

This display of languages has been used to reflect the composition of different ethnic groups and to understand the complexity in the linguistic and cultural contact in a particular locality. Also it has been increasingly used to better understand multilingualism (Gorter, 2006). Gorter's (2006) analysis suggests that there seems to be a creation of symbolic boundaries in the identity construction among different social groups: the (non) English speakers and the (non-) Portuguese speakers in the area. The analysis also suggests that the dominance of English language in the LL texts does not mark the tourist space but is ideologically constructed as a place of luxury and privilege. Employing a similar mixed method approach, Lou (2012) photographed signs, counted the number of occurrences of each language variety, and analyzed policy documents, but he also included participant observations of a China Town steering committee monthly meeting, and in-depth interviews of the key individuals in the committee in his analysis. This analysis allows 
him to conclude that instead of indexing a particular ethno-linguistic group, English often represents identities of corporations, which are involved in the redevelopment of old neighborhoods like China Town.

Moreover, Cenoz and Gorter (2006) examine the LL in two shopping streets of two bilingual cities: Friesland in the Netherlands and the Basque Country in Spain. They compare the uses of State language (Spanish or Dutch), the minority languages (Basque or Frisian), and the international language (English) represented in the signs in relation to the language policies regarding minority language of the two countries. Two hundred and seven units of 975 pictures were analyzed, and the results show the dominance of the state language, but also pointed to the strong language policy to protect the minority languages and also the spread of English as a language of international communication. Following Cenoz and Gorter (2006), Coluzzi (2009) investigated the status of different languages and the extent of the use of some local dialects represented in the signs in two Italian cities: Milan and Udine. He purposefully selected one street in Milan and another in Udine, both of which contain many shops and businesses, and which are mostly frequented by locals. Thus, LL is less influenced by the presence of tourists. One hundred and eighty-eight units from Milan and 200 from Udine were analyzed using a frequency count of the number of occur ences of the languages. He concluded that the LL of the two cities is mostly monolingual with Italian as a dominant language and a moderate presence of English, and that the lack of effective language planning causes the shift to the dominant language and the lack of representation of the local dialects such as Milanese and Friulian.

Also through a LL lens, Huebner (2006) explores issues of language contact, language mixing, and language dominance by analyzing LL data in 15 neighborhoods in Bangkok, Thailand. Six hundred and thirteen signs collected by a team of graduate students were analyzed, and the results show that there is a discrepancy between the government language policies and the pattern of languages used in different communities and promoted by businesses. They also show that the linguistic diversity in the study reflects the nature and the inhabitants of different neighborhoods, and provide evidence of the linguistic influence of English on Thai at the level of lexis, orthography, pronunciation and syntax. Also exploring different patterns of language interaction and the special treatment of English as reflected in the LL, Bruyel-Olmedo and Juan-Garau (2009) surveyed 224 holiday-makers from different countries for their expectations and perceptions of the LL and analyzed 372 seafront photos in S'Arenal in Mallorca, one of the tourist destinations in Spain. They found that English is the most L2 spoken and expected in the signs by the tourists, and that the choices of LL in the area were multilingual and show the privilege position of five languages: Spanish, English, German, Catalan, and French. They also seem to suggest the use of their analysis of the tourists' perceptions of English errors in the signs to improve businesses in the area.

In a similar vain, Kasanga (2012) examines the distributional patterns of the LL in a commercial neighborhood in Phnom Penh, Cambodia in relation to the socio-historical and socioeconomic situation of the country. His data included a small selection of 257 pictures, unstructured interviews with a convenient sample of locals, long-term foreign residents, and a discussion with some educated Cambodians at the Royal University of Phnom Penh. The results show the dominance of the state language Khmer but with a growing multilingualism reflected in the LL. The growing of multilingual signs indicates the vitality of each language represented, especially the growing influence of English seen as a language of modernity, globalization, and superior quality. 
Different from other LL studies that investigate the status and mixing of different languages, Cenoz and Gorter (2008) examine the potential use of LL as an additional source for second language acquisition (SLA). They propose that LL be used as inputs for SLA and the acquisition of multimodal literacy skills and multicompetence. They point to the LL's informative and symbolic function and its multimodality combining visual and printed texts in many languages as important inputs in SLA and literacy skills. Similarly, Sayer (2010) suggests the potential benefits of using LL as pedagogical resources for teaching EFL students after his qualitative content analysis of 250 photos of signs, billboards, posters, and banners for the social meaning of English in Oaxaca, Mexico.

Many of the studies reviewed above have shown the LL's reflection of the ethnic group composition and the multilingual situation of a particular locality. They have also pointed to the dominance of English, associating it with power and privileges. Moreover, they illustrated the LL's potential as resources for language and literacy development. In contribution to the body of knowledge of the LL literature, this study examines the status of languages, the language-incontact situation, and the functions of Khmer as a minority language through signs in a Cambodia Town in the United States, which is new to the linguistic landscape research community.

\section{Research Questions}

This article reports on a study of the role of Khmer language and its contact with English through the linguistic landscape (LL) data of a newly recognized Cambodia Town in Lowell, Massachusetts. It aims to better understand the multilingualism of the community, the role of the Khmer language, and the English-Khmer language-in-contact situation as reflected in public and store signs in the city. This study is guided by the following research questions:

1. What languages are used in the signs in Cambodia Town in Lowell, MA?

2. What are the functions of Khmer (Cambodian) in the signs?

3. To what degree does transliteration occur between Khmer and English in the signs?

\section{Methodology}

This research was conducted out of my interest in the signs in a newly recognized Cambodia Town in Lowell, Massachusetts. I am a first generation Cambodian, speaking Khmer as a native language. I have been in the United States for more than 7 years, mostly as a graduate student (M.A. in TESOL in California and Ph.D. in Culture, Literacy, and Language in Texas). While in the United States, I have been in close contact with and visited relatives and friends in different Cambodian communities in California, Washington, Texas, and Massachusetts. I have also been invited twice as a speaker to Cambodian-American communities in Washington and Ohio. With these experiences, I have developed a good knowledge of and a keen interest in CambodianAmerican communities in the United States.

Lowell is a city located in the Middlesex county of Massachusetts with a total population of about 110,000 in 2015 . The population consist of people from different ethnic and linguistic backgrounds. The 2015 U.S. Census, as seen in Figure 1 below, estimates Whites to be the largest 
group with 49.5\%, followed by Asian Americans, Hispanics, and African Americans at 21.3\%, $18.1 \%$, and $6.8 \%$ respectively.

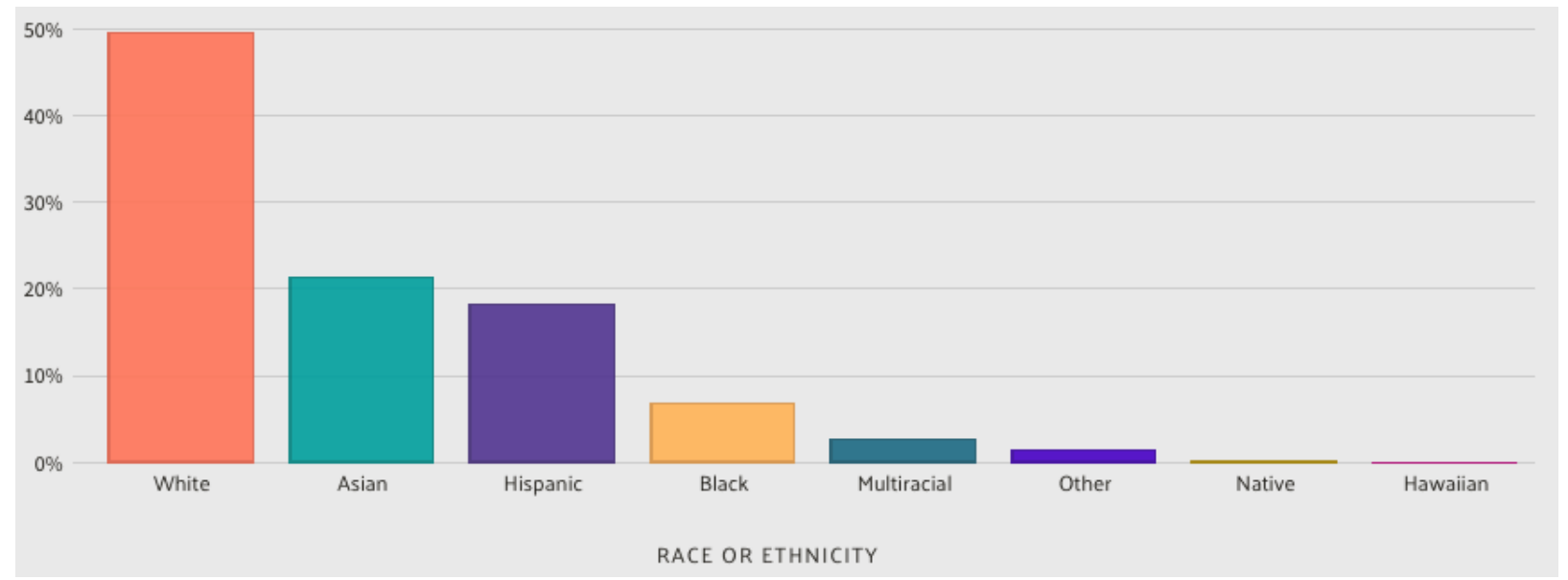

Figure 1. Population by Race or Ethnicity in Lowell in 2015 (datausa.io)

Cambodian Americans make up the largest group among the Asian subgroups, and according to Aung and Yu (2007), the influx and resettlement of Cambodian refugees drawn by the high-technology boom of the early 1980s makes Lowell a city with the second largest Cambodian population in the United States after Long Beach, California. The 2010 Census puts the Cambodian population in Lowell at about 13,000 which was about $12.5 \%$ of Lowell's total population. However, Cambodian community leaders there give a higher estimate of the total Cambodian population at between 25,000 and 35,000. This discrepancy in the data may be due to "language and cultural barriers, fear of immigration consequences and general fear of government due to Khmer Rouge atrocities, and lack of outreach and insufficient translation" (Aung \& Yu, 2007, p. 90). According to Ly (2011), more than 20,000 Cambodians reside in Lowell, constituting about a quarter of the total population, which is about the same estimate of the Cambodian community leaders. This large Cambodian population is also reflected in the fact that Mon-Khmer or Cambodian language is the second largest minority language after Spanish in Lowell according to the 2015 U.S. Census estimate. This estimate is shown in Figure 2 below with other languages spoken in Lowell.

With an increasingly large population of Cambodians residing in the city of Lowell, the community made efforts to establish a Cambodia Town to recognize the contribution of the Cambodian American community and to elevate interest in the area and increase civic pride. The Cambodia Town was officially recognized on April 4, 2012. Its preparation included "sign and façade improvement, the installation of 'gateway signs,' and renovations and upgrades to Roberto Clemente Park, to include placing Cambodian artwork on the new concession stand and the dedication of the Pai-Lin Volleyball Courts" (Lowell, 2012). Image 1 contains four photos that give an overview of the linguistic landscape of Lowell city.

Data for this research include 279 photos collected during the summer of 2013 in Lowell, MA with a Canon digital camera (PowerShot A620 with 7.1 megapixels). They include mostly store and office fronts, advertisement stickers and posters found on doors, windows, walls or lampposts. Secondary data include a menu from a Cambodian restaurant, a Khmer-English newspaper, my personal experience living with and interacting with local Cambodians and watching local TV broadcasting in Khmer in the community. All photos were collected from two 
important main streets (Westford Street and Branch Street) at the heart of the Cambodia Town with many Cambodian businesses. The black rectangular line on the map in Image 2 shows the area of the two streets (Middlesex and Westford) from which the data were obtained. As suggested in Leeman and Modan (2010), the site for this data collection was purposefully selected because of its location in the Cambodia Town with many Cambodian businesses and offices as identified by two Cambodian residents in Lowell, one of whom is a long-term resident and has been living in the area for more than 25 years, and another a graduate student from Cambodia who has moved to work in the city for a little over 5 years.

Like in many other LL studies, I struggled to make decisions on the unit of my analysis. Huebner (2009) mentioned the lack of an agreed-upon or a clearly identified definition of a unit of analysis, but seemed to suggest Backhaus' (2006) definition putting a unit in a spatially definable frame. I adopt this definition and consider everything contained in one frame, big or small, as one unit or sign. One photo then may contain more than one unit of analysis. Image 3 shows two examples of a photo that contains more than one unit of analysis. The photo on the left has two units, and the one on the right has three. I noticed a number of signs overlap, but because I took them in different places I decided to count each one as a separate unit. In the 279 photos, a total of 332 units were identified and analyzed for this project.

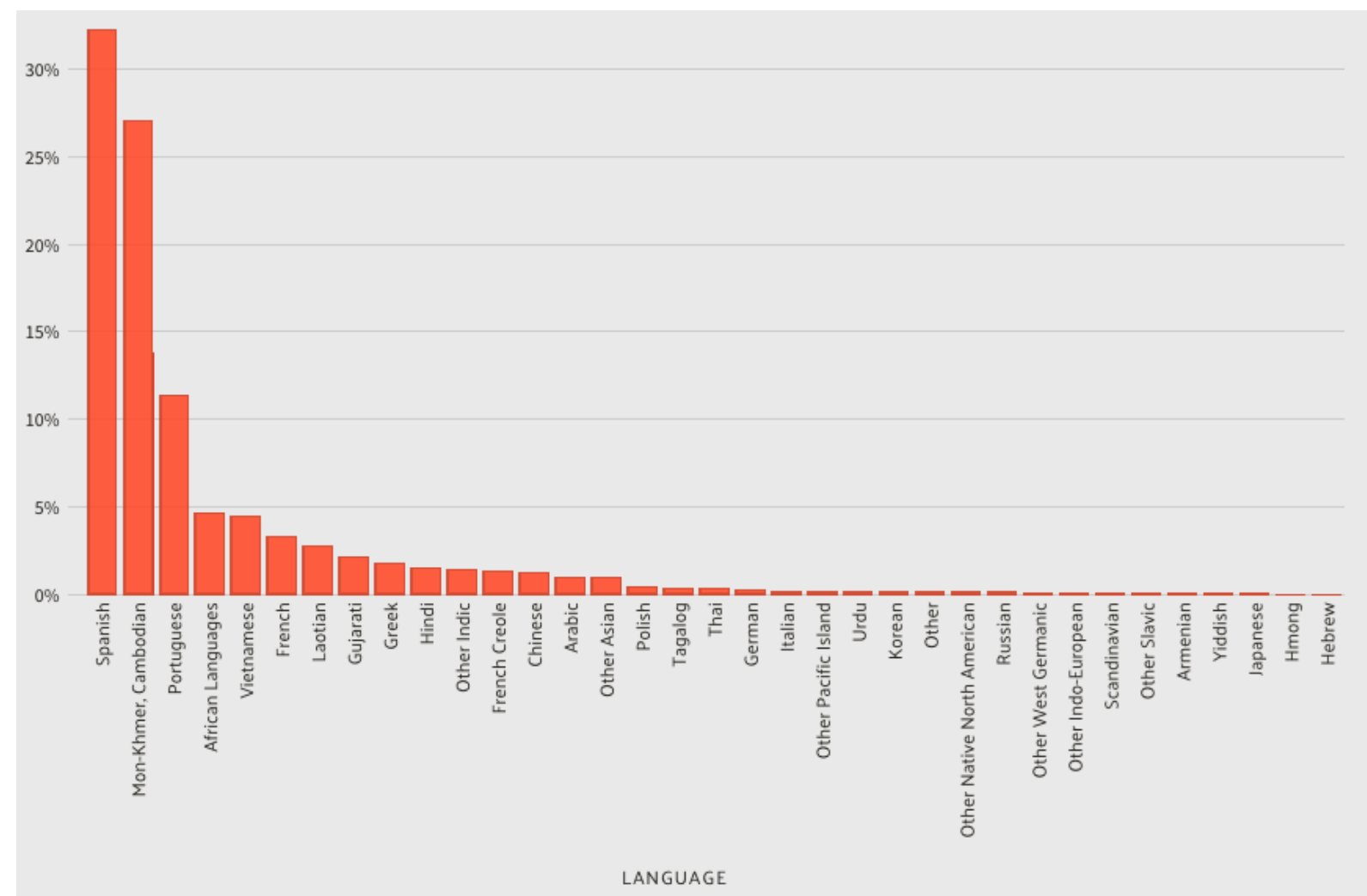

Figure 2. Languages spoken in Lowell city (datausa.io) 


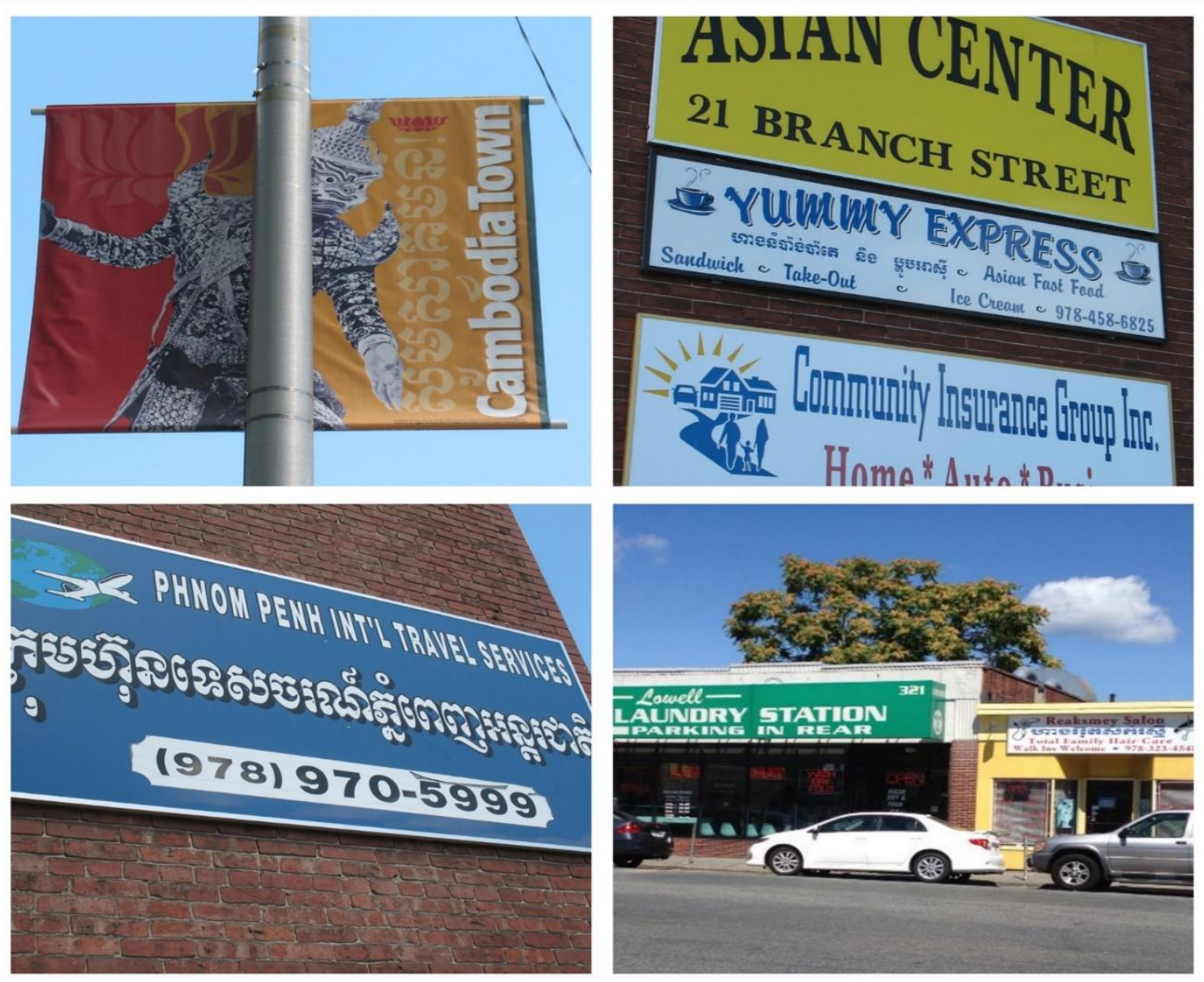

Image 1. Linguistic landscape of the Cambodia Town in Lowell, Massachusetts

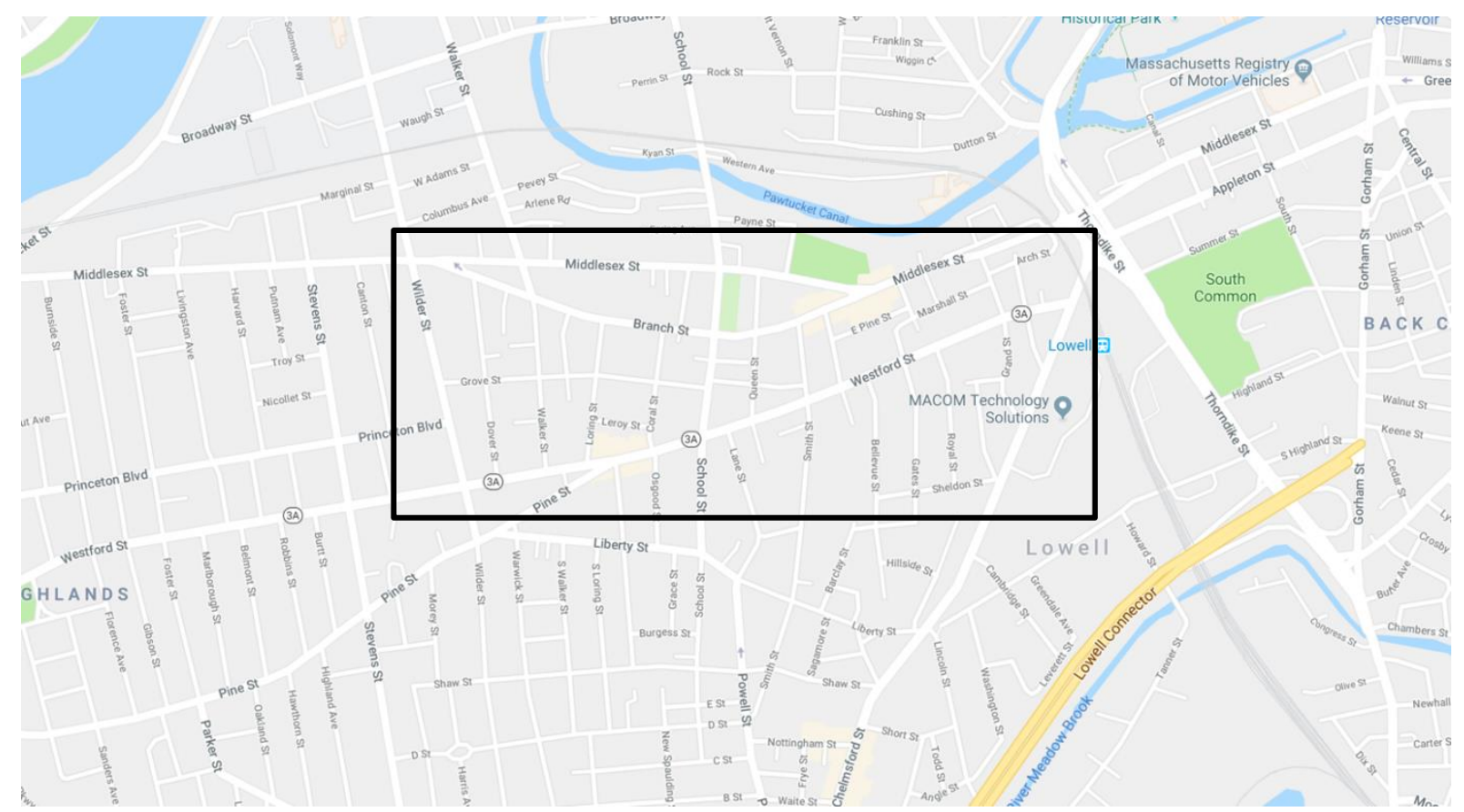

Image 2. Research site (adapted from Google maps) 

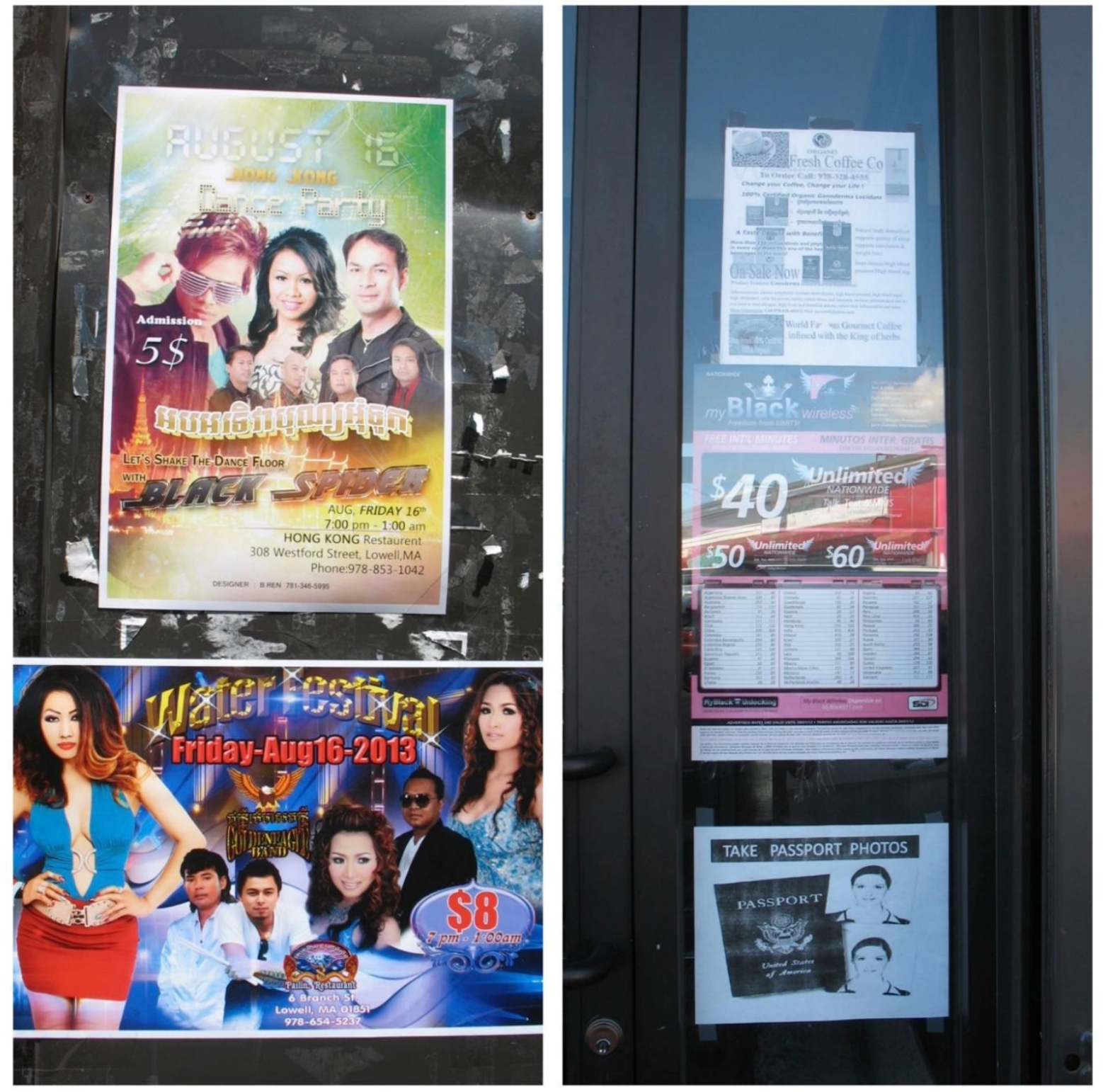

Image 3. Photo on the right with 2 units of analysis and left with 3 units

All the photos were coded using NVivo, a qualitative data analysis software program. Each unit was coded based on the language(s) used in the signs and their monolingualism or multilingualism. Content analysis and semiotics (Silverman, 2006) are used for data analysis. At the beginning, a simple counting of the number of occurrences of each language was done to see their representativeness in the signs. As suggested by Coluzzi (2009) this counting of signs is an important first step in LL analysis. Each unit was also coded as a monolingual or multilingual sign, where only one language is used in monolingual sign and two more languages are used in multilingual signs. To examine the functions of Khmer language, all the units in which Khmer is used were sub-coded using the two functions of LL - informational and symbolic identified by Landry and Bourhis (1997). These functions will be further discussed in the result section. Moreover, to examine the dominance of Khmer and English in relation to each other, all the 
multilingual signs with Khmer and English were sub-coded as: Khmer-dominant, Englishdominant, and Khmer-English-balance depending on the visibility and density of each language. These are illustrated in Image 4. On the top left sign, English is more visible and English words are more dense in comparison to Khmer, so this sign was sub-coded as an English-dominant sign. The sign on the right was sub-coded as a Khmer-dominant sign because Khmer language is more visible and Khmer words are more dense than English. Words in the bottom left sign is an example of a Khmer-English-balance sign, where the visibility and density of words in Khmer and in English are equal, and they communicate exactly the same message. Moreover, using Huebner's (2006) examination of language-in-contact as a frame of reference, I coded any influence of English on Khmer and Khmer on English at the level of orthography, lexis, or syntax as transliteration to better understand what the language-in-contact (English and Khmer) situation is like in this newly recognized Cambodia Town.
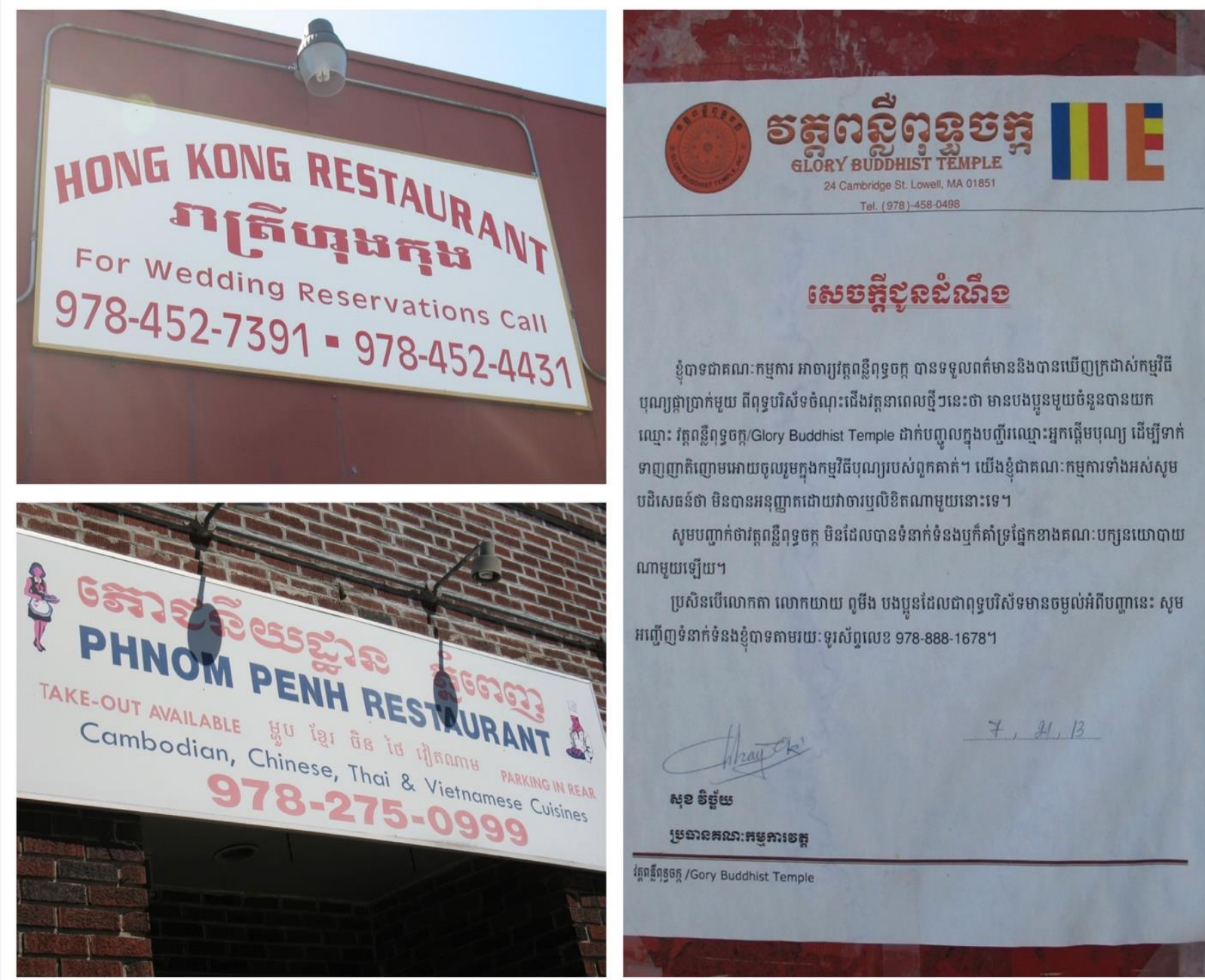

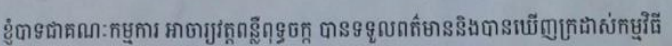

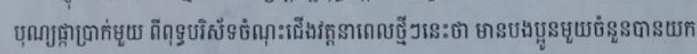

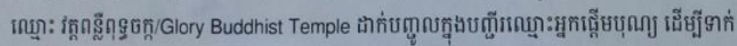

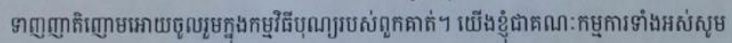

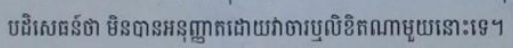

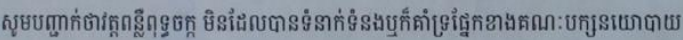

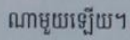

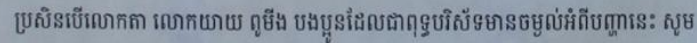

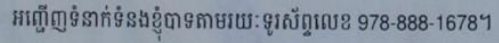

Image 4. Top-left English-dominated, Bottom-left Khmer-English-balance, Right Khmerdominated 


\section{Results}

\section{Languages Used in Signs}

In order to answer my first research question (What languages are used in the signs in Cambodia Town in Lowell, MA?), I did a frequency count of all the languages represented in the signs. It is important to note here that a sign may contain more than one language, so the total number of signs contain more than the 332 units being analyzed. The frequencies and percentages of different languages represented in the signs are shown in Table 1.

Table 1. Frequencies and Percentages of Different Languages Represented in the Signs.

\begin{tabular}{lrr}
\hline Language & \# of Signs & $\%$ \\
\hline English & 260 & 61.76 \\
Khmer & 123 & 29.22 \\
Lao & 14 & 3.33 \\
Vietnamese & 10 & 2.38 \\
Spanish & 5 & 1.19 \\
Mandarin & 4 & 0.95 \\
Thai & 3 & 0.71 \\
French & 2 & 0.48 \\
\hline Totals & 421 & $100 \%$ \\
\hline
\end{tabular}

According to Table1, English is used in 260 signs accounting for more than $60 \%$. This is not surprising considering its dominance in the United States. and the world. Khmer appears in 123 signs which is about $30 \%$, followed by Lao $3.33 \%$ and Vietnamese $2.38 \%$. Other languages that represent less than $2 \%$ include Spanish, Mandarin, Thai, and French. These languages appear in both monolingual and multilingual signs. Monolingual signs are those in which only one language is used while multilingual signs contain two or more languages. Table 2 shows the frequencies and percentage of the monolingual and multilingual signs.

Table 2. Multilingualism of the Signs.

\begin{tabular}{lrr}
\hline Signs & \# of Signs & $\%$ \\
\hline Monolingual & 187 & 56.33 \\
Multilingual & 145 & 43.67 \\
\hline Totals & 332 & $100 \%$ \\
\hline
\end{tabular}

According to Table 2, 187 signs or $56.33 \%$ are monolingual and 145 signs or $43.67 \%$ are multilingual. One hundred and fifteen (almost $80 \%$ ) of the 145 multilingual signs contain Khmer and English, and they are used to analyze the dominance of Khmer in comparison to English in terms of their visibility and density in the signs. The result is illustrated in Figure 3. 


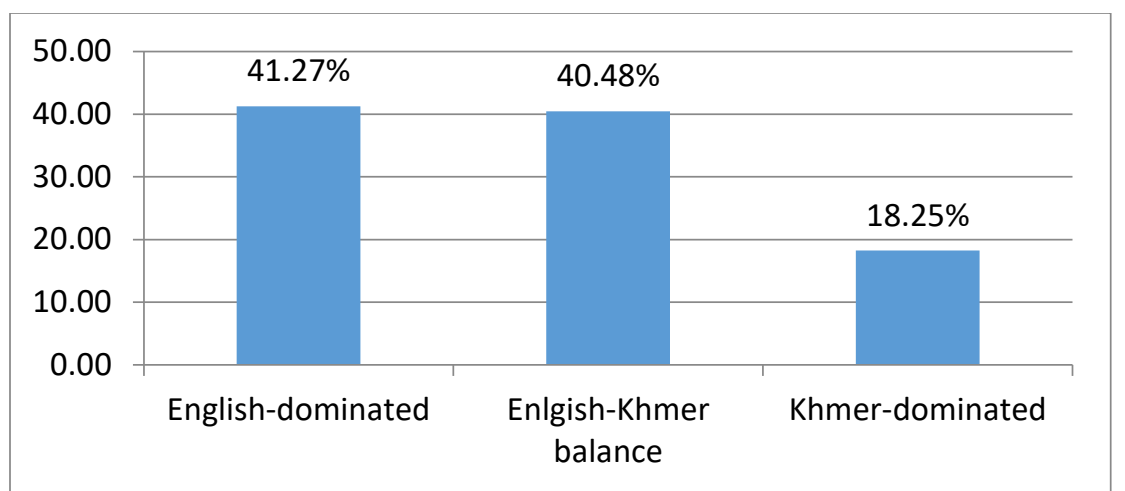

Figure 3. The dominance of Khmer in comparison to English in terms of visibility and density in Khmer-English bilingual signs

According to Figure 3, English dominates $41.27 \%$ of the 115 multilingual signs while Khmer dominates only $18.25 \%$ of the signs. In the other $40.48 \%$ of the signs, Khmer and English are equally visible and dense. Image 4 provides illustrations of these three types of multilingual sign. The dominance of English is still prevalent in these multilingual signs. Next I turn to my second research question that examines the symbolic and informational functions of Khmer language in the signs.

\section{Functions of the Khmer Language in the Signs}

In this section, Khmer language found in the multilingual and monolingual signs is examined in terms of its functions to answer my second research question: What are the functions of Khmer (Cambodian) in the signs? According to Landry and Bourhis (1997), a language in signs can be used to serve two important functions: symbolic or informational. The symbolic function of a language focuses on the uses of a language in signs for value and status in relation to other languages as seen in Image 5. The use of Khmer language together with the visual in this image can serve an important purpose of marking geographical boundaries of the language community; "thus the linguistic landscape serves to inform in-group and out-group members of the linguistic characteristics, territorial limits and language boundaries of the region they have entered" (Landry \& Bourhis, 1997, p. 25). The informational function, on the other hand, includes its uses for communicating or obtaining services as illustrated in Image 6, in which Khmer is used to provide information about the different services available at a travel agency. In some instances, Khmer performs both of these functions. Figure 4 shows the percentage of the signs in which Khmer is used to perform each of these functions.

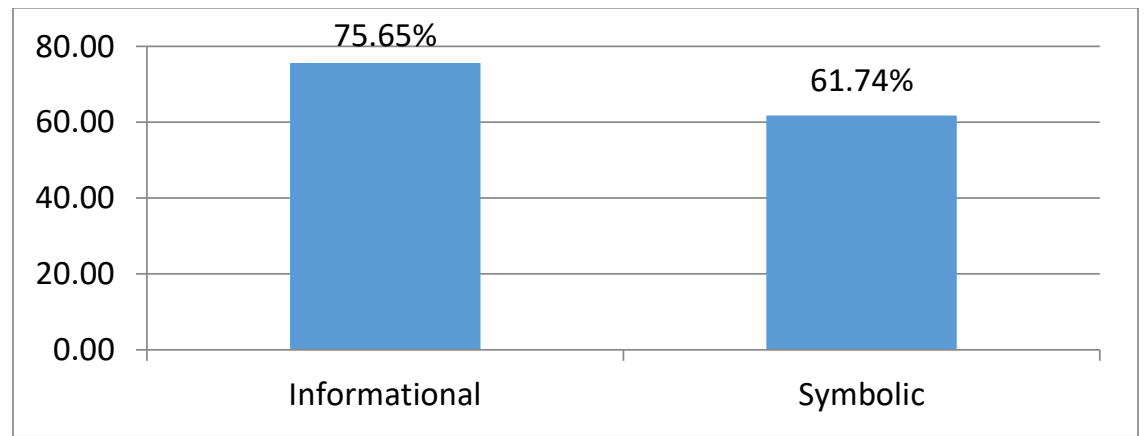

Figure 4. Percentage of the functions of Khmer in the signs 
Figure 4 shows that Khmer is used for both functions: informational and symbolic. The informational function of Khmer accounts for $75.65 \%$ of the total 125 monolingual and multilingual signs, and the symbolic function $61.74 \%$. It is interesting to note that when Khmer is a dominant language in the signs, it is mostly used to provide information, but it is used for both functions in the signs with English dominated and those with equal visibility and density of English and Khmer. This is illustrated in Table 3. According to the Table 3, Khmer is used for informational function only in all $22 \mathrm{Khmer-dominated} \mathrm{signs,} \mathrm{but} \mathrm{performs} \mathrm{both} \mathrm{informational} \mathrm{and}$ symbolic function in the other signs.

Table 3. Cross-tabulation between the Dominance of Language and the Use of Khmer in KhmerEnglish Bilingual Signs.

\begin{tabular}{lrr}
\hline Dominance and Use of Khmer & Informational & Symbolic \\
\hline English-dominated & 11 & 18 \\
English-Khmer balance & 20 & 12 \\
Khmer-dominated & 22 & 0 \\
\hline
\end{tabular}

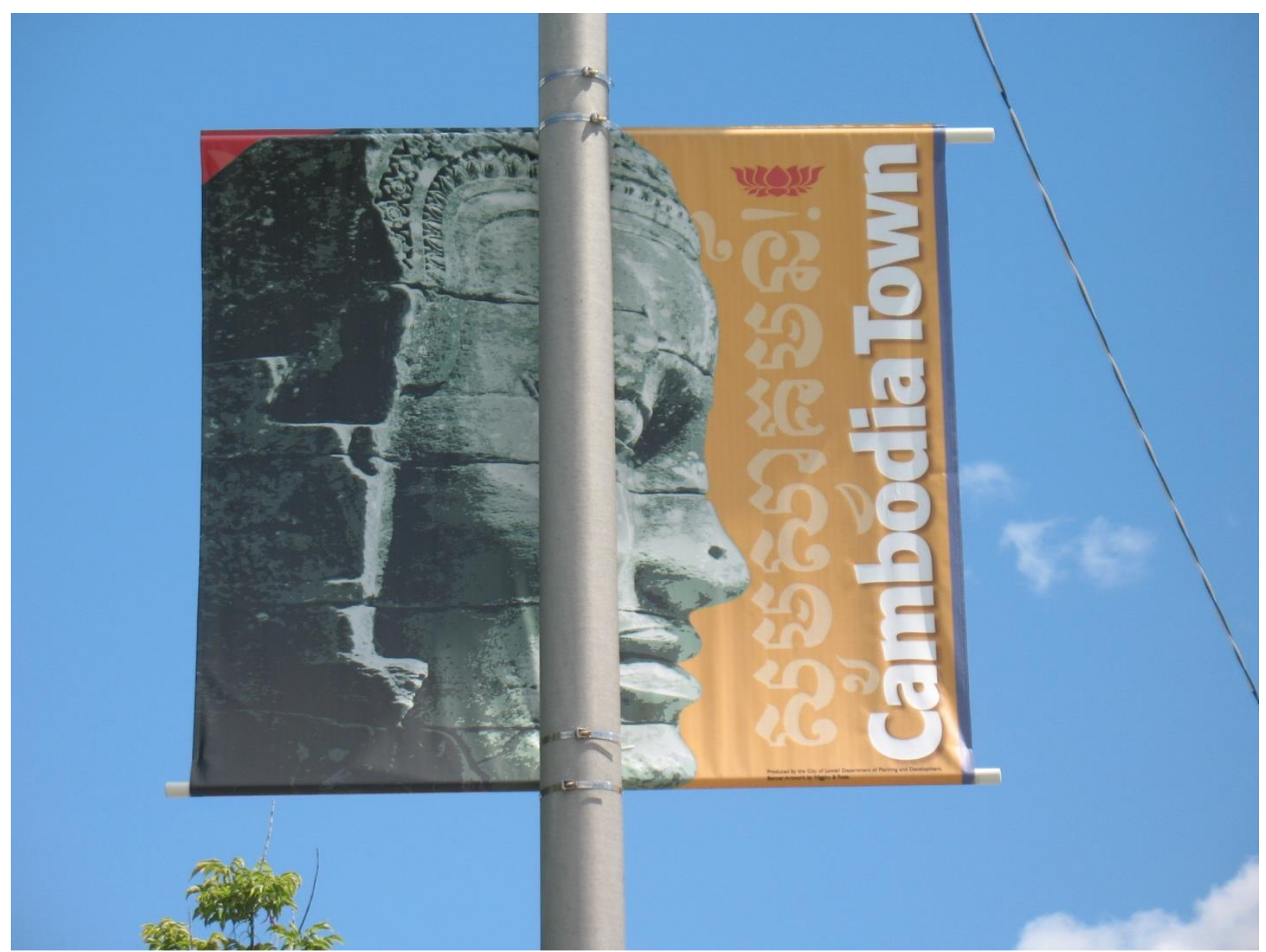

Image 5: Symbolic use of Khmer

Image 5 is one of the four images, hanging on the light poles on the bridge connecting the downtown area of Lowell to Cambodia Town. It has the word "Cambodia Town" in English and the Khmer word "ญูษญูกษ์ ("welcome" in English). They are put together with a big smiling 
face of Ta Prum, the sculpture found among the oldest temples in Cambodia and well-known among Cambodians and tourists to Cambodia. The use of Khmer together with the image in the sign in this example serve an important symbolic function to mark the entrance of a Khmerspeaking community. The other symbolic uses of Khmer include restaurant, jewelry and other store names such as "ปี้ษิs" ("Pailin," the name of one of the provinces in Cambodia well-known

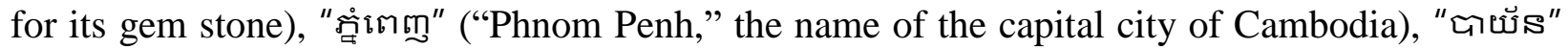
("Bayon," the name of one of the oldest temples in Cambodia), and "รษยภภ" ("Apsara," a Khmer word referring to the well-known angels chiseled into the stone walls of the famous Angkor Wat temple). The use of these names together with some images such as the Pailin gem stone, the four faces of Ta Prum, and the Apsara angels typically found on the walls of Angkor Wat temple symbolizes Cambodian products and culture and more importantly mark the Khmer language community. This symbolization serves an important function of attracting interests in the Cambodian American communities and of recreating home away from home for many Cambodian Americans who were forced to fleE their own country in the 1980s. For tourists and investors who may be interested in different aspects of Cambodian culture before going to visit Cambodia, Cambodia Town may be a choice. In addition to having all the restaurants, jewelry and grocery stores that closely resemble those in Cambodia, Cambodia Town also houses one Buddhist temple that offers different religious services for the community, the Cambodian Mutual Assistance Association (CMAA) which organizes different cultural events for the community, and the Royal Honorary Consulate of Cambodia. For many Cambodian Americans, the Khmer names of different restaurants and stores and their different products resemble many of the restaurants, stores, and products back in Cambodia.

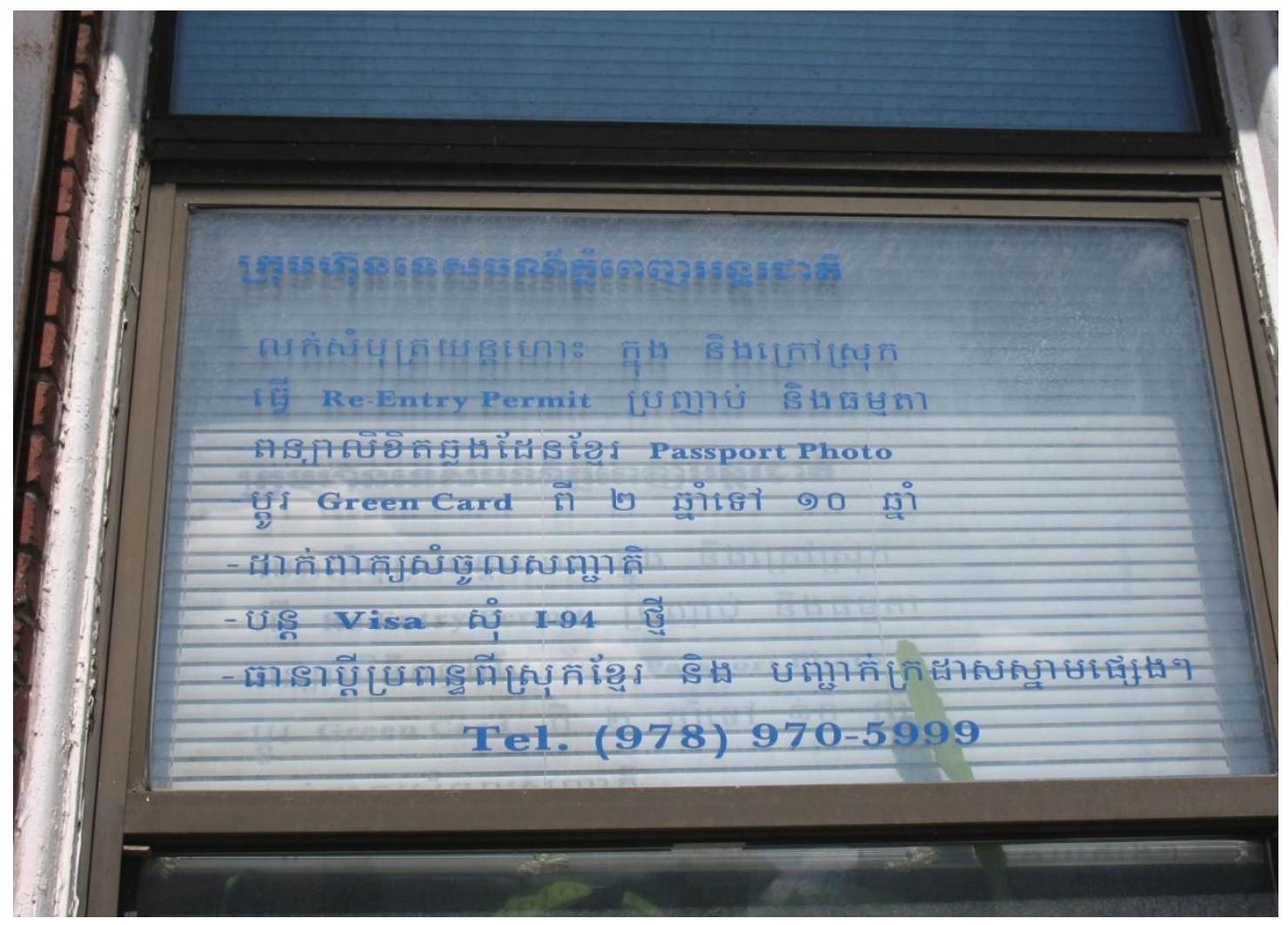

Image 6. Informational function of Khmer 
Image 6 shows the use of Khmer to provide information; this is found on one of the windows of a travel agency. It translates into English as follows (original in bold):

Phnom Penh International Travel Agency

Sell national and international air tickets

Get re-entry permit fast and normal

Extend Cambodian passport Passport Photo

Change green card from 2 years to 10 years

Apply for citizenship

Extend visa and request new I-94

Assist in documents to help husband or wife from Cambodia and certify other documents.

Tel. (978) 970-5999

This use of Khmer serves the purpose of communicating information about the products and services available at the travel agency and clearly targets people who read and understand Khmer in the community. It is also interesting to note the use of English words and phrases such as reentry permit, Passport Photo, green card and visa together with Khmer in this sign most likely reflects the Khmer-English bilingual ability of people in the community. In the next section, I will examine the language-in-contact situation in the signs.

\section{Transliteration Between Khmer and English}

In this section, I examine the use of Khmer-English translations within the signs and the transliterations between the two languages at the level of orthography, lexis, and pronunciation in the Khmer-English bilingual signs to answer my third research question: to what degree does transliteration occur between Khmer and English in the signs? Translation is a function in a sign where a language is used to tell the meaning of words in another language such as those illustrated in Image 7, while transliteration refers to the use of one orthographic system to record similarsounding letters or words in another system such as those illustrated in Image 8. Figure 5 shows the percentage of the amount of translation and transliteration found in the Khmer-English bilingual signs.

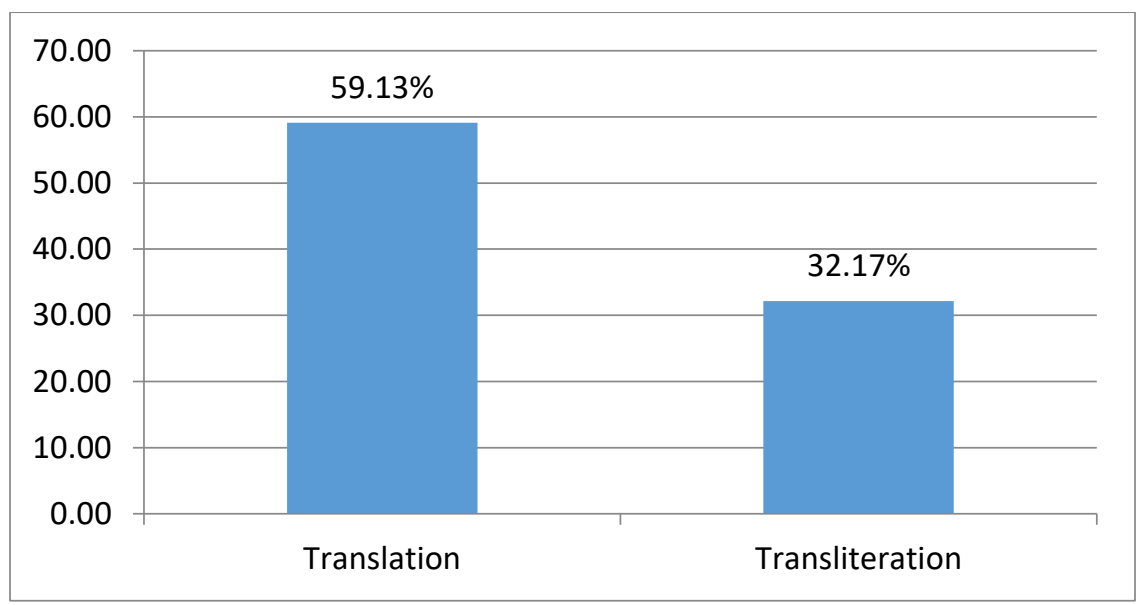

Figure 5. Percentage of the use of Khmer and English for translation and transliteration of each other 
Figure 5 shows that $59.13 \%$ of the total 115 Khmer-English bilingual signs contains the translation function of both Khmer and English, and 32.17\% consists of word borrowing and the use of one orthography to write words in another language between Khmer and English. Translation occurs both ways; Khmer is translated into English when it is the dominant language in the sign, and vice versa. Some translations are only partial and done on the parts of the signs that provide information. For instance, the top right of Image 7 is a recruitment advertisement of the Lowell Police Department, which provides information about the recruitment in English and a Khmer translation. The top left is a window of a hair salon providing a list of its services in English followed by a Khmer translation. At the bottom of Image 7 is a logo which says the Royal Honorary Consulate of Cambodia in Khmer on top and its English equivalent below it. This translation accounts for a large number of the bilingual signs, which reflects the different ethnic groups and the increasing bilingualism in Lowell.

In addition to the translation function between Khmer and English, the bilingual signs contain a large number of examples of the transliteration between the two languages including the word borrowing and the use of Khmer orthography to record the English words. For instance, the top left of Image 8 is a recruitment advertisement of a café, in which Khmer orthography is used to record the sound of the word eggroll instead of using the Khmer translation of the word. The top and bottom right of the image illustrate the same process with the words city and yummy; instead of using the Khmer translation, the Khmer orthography is used to record the sound of these words. In these three cases, the transliteration is used instead of the Khmer translation because the words eggroll, city and yummy are probably used as names here. For instance, all the letter are capitalized in "EGGROLL CAFE", and the name is placed on the left of its logo; the same is true for "LOWELL CITY Video/DVD," and "Welcome to Yummy" as translated from Khmer clearly indicates Yummy as the name of the restaurant. On the bottom left of Image 8 is on information sticker at a local grocery, which provides a good example of word borrowing. The English word "food stamp" has no direct equivalence in Khmer, so the Khmer word above it which also reads "food stamp" is obviously borrowed from English, using Khmer orthography to record the sound of the English word.

The transliteration examples in the bilingual signs include not only the use of Khmer orthography to write the English words, but also the use of English orthography to write the Khmer words, particularly the proper nouns such as names of cities and provinces. Image 9 illustrates these examples. On the top, the word "Pailin" uses English character to record the sound of a Khmer word which refers to a name of the province in Cambodia. The same process can be found in the words "Thydasour" in the middle and "Bayon" at the bottom of the image. Thydasour is a popular name for girls in Cambodia and it can also mean heavenly angel, and Bayon is the name of one of the oldest temples in one of the most famous tourist destinations in Cambodia. These transliterated versions of the Khmer words are mostly found on storefronts with proper nouns such as Pailin and Bayon, but there are also examples of the use of direct translation instead of this

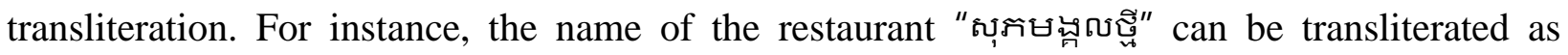
Sopheak Mongkol Thmey, but it uses the English translation "New Happiness Restaurant" instead. 


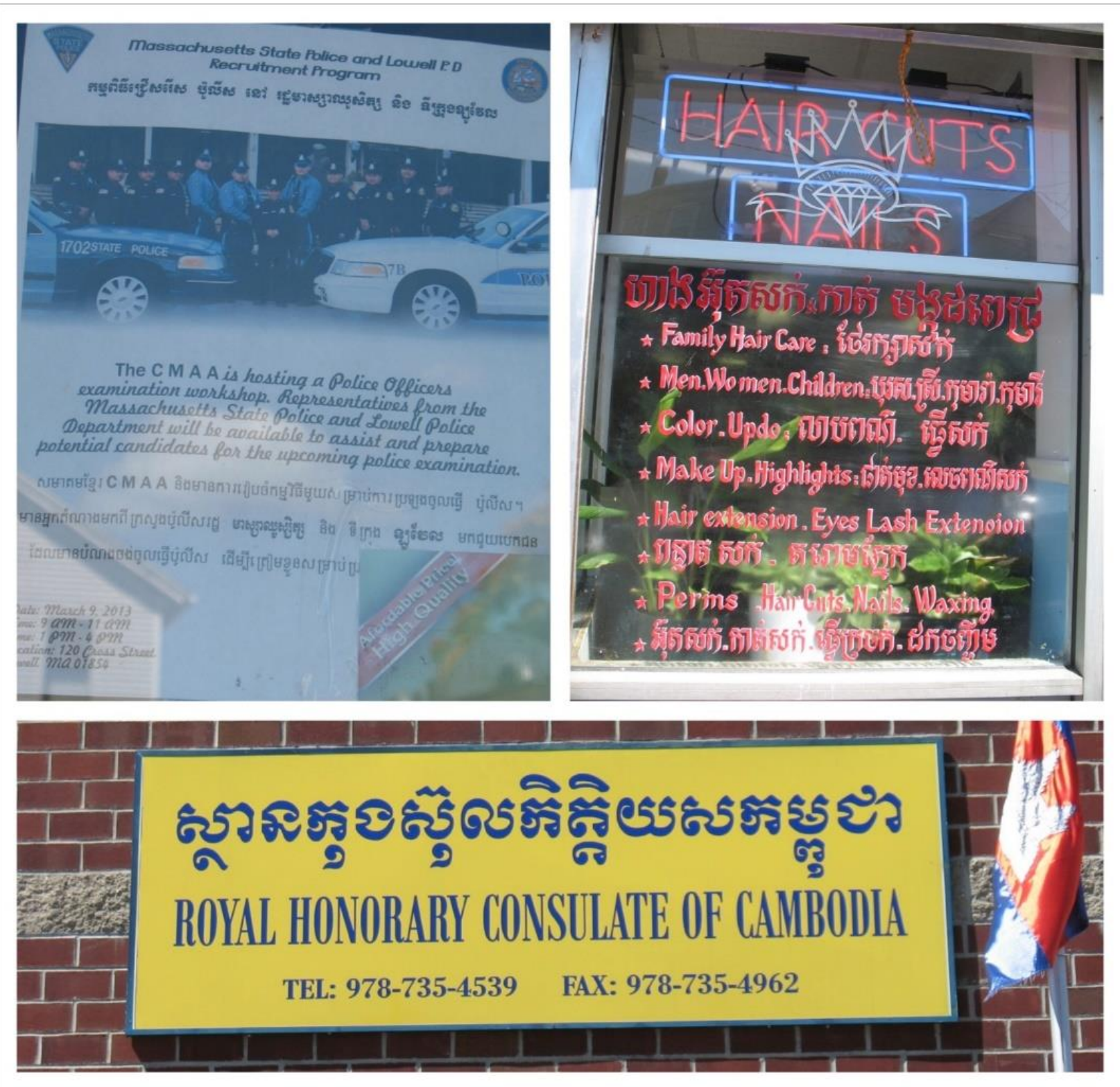

Image 7. Khmer and English translating each other

\section{Discussion and Conclusion}

This paper examined the multilingual situation, the function of Khmer as a minority language, and the language-in-contact situation between Khmer and English of the signs in one part of Lowell, MA recently recognized as a Cambodia Town. It is not surprising to find English to be the dominant language in the signs since it is the mainstream language in the United States and, according to Clayton (2006), seems to be spreading purposefully in many countries around the world. However, the data seem to suggest the increasing multilingualism in the signs with many minority languages represented including Khmer, Lao, Thai, Vietnamese, Mandarin-Chinese, French, and Spanish. This growth in multilingual signs, according to Kasanga (2012), indicates 
the importance of each language represented, particularly Khmer, which is a native language of many first-generation Cambodian Americans in Lowell.
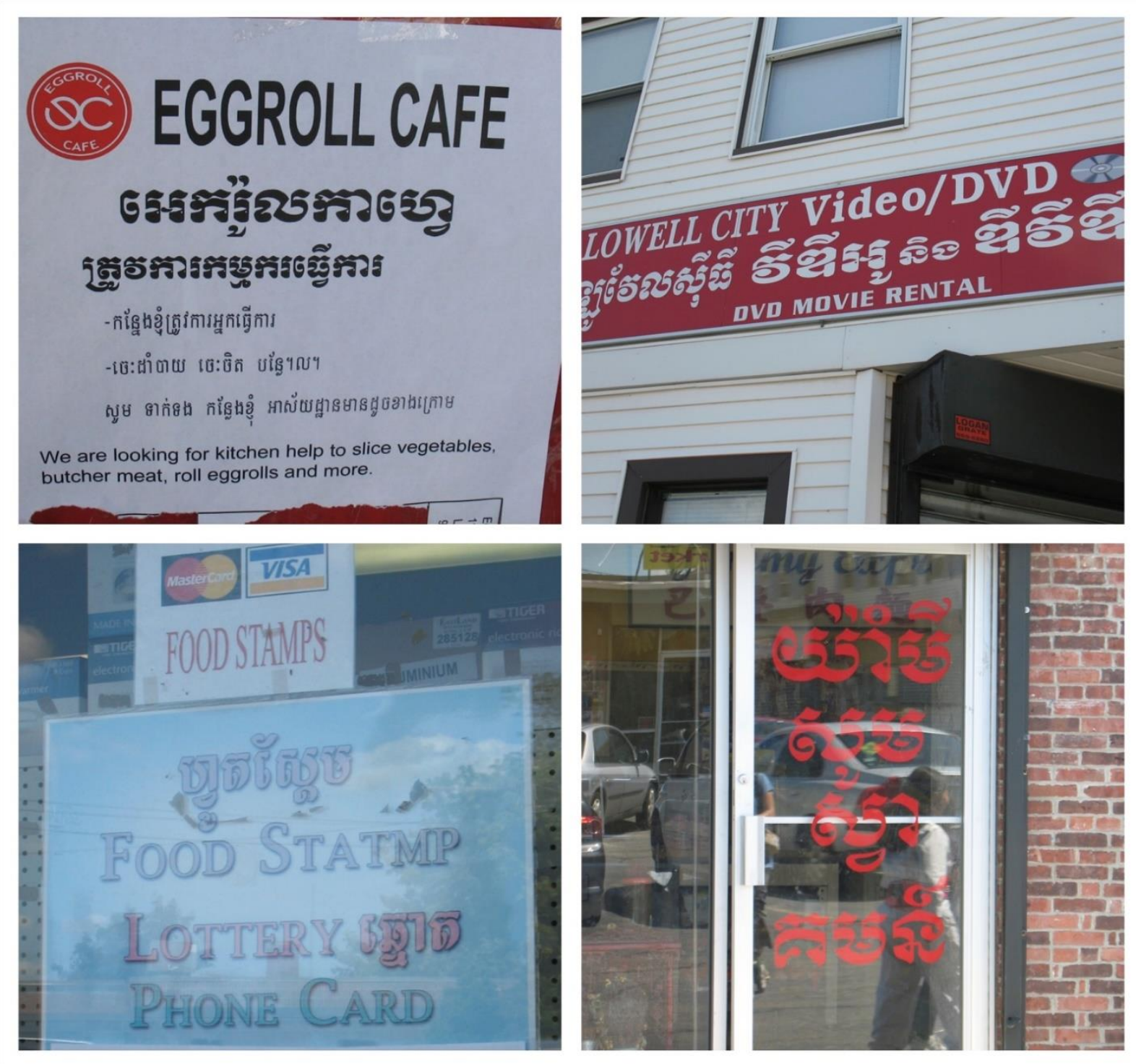

Image 8. Transliteration: using Khmer orthography to write English words

The use of Khmer in many of the bilingual signs may suggest a certain level of language planning from the Cambodian community, one of the largest minority populations in the area. Although Khmer is used for informational functions in most of the bilingual signs, its symbolic uses such as the popular provincial names and cities and other semiotics such as the use of the faces of Ta Prum show the community's desire to represent their cultural identity. This desire is further illustrated in the Lowell Southeast Asian Water Festival celebrated every August, in which many of the Cambodian traditions, including the boat race together with the traditions of other Southeast Asian countries, are shown (see http://www.lowellwater festival.com for more information on the festival). 

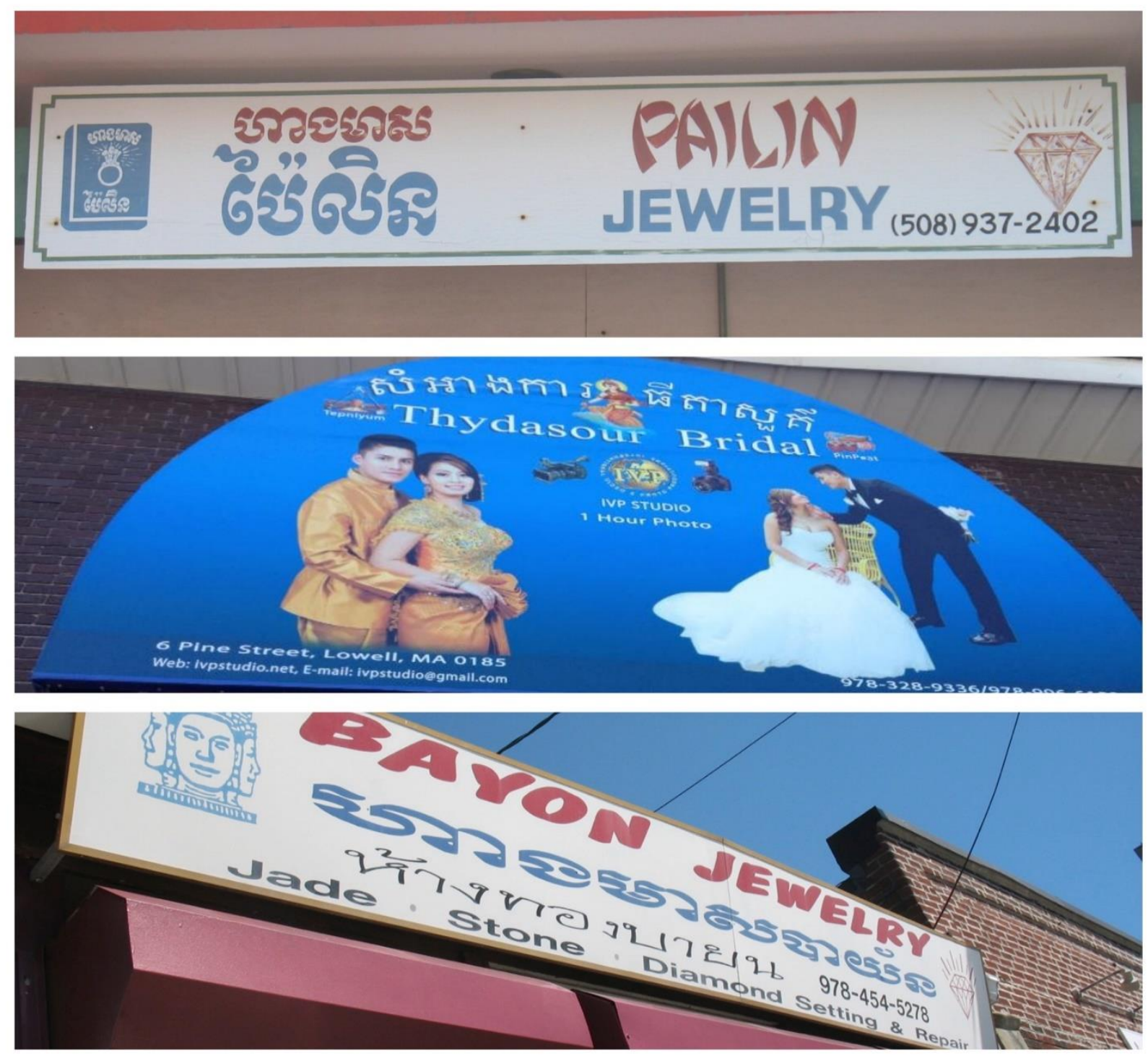

Image 9. Transliteration, using English orthography to write Khmer words

Moreover, the informational function of Khmer in the bilingual signs is directed to the Cambodian residents and suggests that Khmer is being used in their everyday communication. This is also confirmed by my experience immersing in the community, where I learned that at least one Khmer-dominant Khmer-English newspaper and one Khmer-speaking TV channel are in operation. I also witnessed Cambodian adults in the neighborhood using Khmer with their young ones and singing Khmer karaoke on different occasions. These many domains of Khmer language use operate, both symbolically and functionally, as what Gorter (2006) refers to as symbolic boundaries, in this case, of the Cambodia Town. I also see it as the community's planning for language maintenance. But how successfully they have maintained their heritage language will require further research. More investigations may need to be done to examine the language use in different domains such as in the formal and informal schooling system of the community.

In addition to the increasing multilingualism that the signs reflect, the linguistic landscape of this part of the city also suggests an interesting language-in-contact situation between Khmer as a minority language and English as the dominant language. Similar to the language-in-contact 
situation in Bangkok (Huebner, 2006), the current study has also found that the influence of Khmer and English on each other occurs at the level of lexis, orthography and pronunciation, but English seems to exert more influence especially in terms of its vocabulary being borrowed and recorded using Khmer orthography. Language-in-contact situations like this are unavoidable throughout time; however, without proper language planning, Khmer language in Lowell could deviate significantly from standard Khmer. As seen in the examples of the transliteration in the bilingual signs, only proper nouns in Khmer, such as names of cities and provinces, are transliterated using English orthography; however, the common nouns in English are directly borrowed and used as Khmer words with Khmer orthography recording the sound of those English words. The already existing Khmer equivalent of those English words are not used. This may have interesting implications for Khmer language acquisition and learning for the second and third generation of Cambodian-Americans.

Moreover, many of the signs in this study can be a good source of language input particularly for heritage language learners, such as the second and third generation of the Cambodian-Americans in the community. Cenoz and Gorter (2008) suggest that because of their multilingualism, multimodality and social context, the signs are good additional inputs for second language acquisition and literacy skill development. For Cambodian-Americans who are trying to teach their children Khmer language at home or through after-school Khmer heritage language program, these signs may be a good additional source for exposure to the heritage language. The signs can also be used as a resource for student-led projects such as those suggested by Sayer (2010), where students examine the social meaning and function of language. This is particularly applicable for a heritage language context.

This study is not without limitations. Considering the small scope of this linguistic landscape study, any generalization of the results may need to be done cautiously. Also it is important to know that this type of study is generally synchronic since the landscape may change throughout time. Therefore, further research using similar data should also examine other aspects of the signs, including the bottom-up/top-down or governmental/commercial nature of the signs, and their target audiences. It may also be good to include other sources of data such as policy documents on the planning of city signs and interviews of stakeholders in the community to examine the issues in language planning from multiple perspectives.

\section{References}

Aung, K. M., \& Yu, N. (2007). Does the system work for Cambodian American students? The educational experiences and demographics of Cambodians in Lowell, Massachusetts. In T.-L. Pho, J. N. Gerson, \& S. R. Cowan (Eds.), Southeast Asian refugees and immigrants in the Mill City (pp. 88-111). Burlington, VT: University Press of New England.

Backhaus, P. (2006). Multilingualism in Tokyo: A look into the linguistic landscape. International Journal of Multilingualism, 3(1), 52-66.

Ben-Rafael, E., Shohamy, E., \& Barni, M. (2010). Introduction: An approach to an ordered disorder. In E. Shohamy, E. Ben-Rafael, \& M. Barni (Eds.), Linguistic landscape in the city (pp. xi-xxviii). Cornwall, UK: MPG Books Group.

Bruyel-Olmedo, A., \& Juan-Garau, M. (2009). English as a lingua franca in the linguistic landscape of the multilingual resort of S'Arenal in Mallorca. International Journal of Multilingualism, 6(4), 386-411. doi: 10.1080/14790710903125010 
Cenoz, J., \& Gorter, D. (2006). Linguistic landscape and minority languages. International Journal of Multilingualism, 3(1), 67-80.

Cenoz, J., \& Gorter, D. (2008). The linguistic landscape as an additional source of input in second langauge acquisition. IRAL, 46, 267-287. doi: 10.1515/IRAL.2008.012

Clayton, T. (2006). Language choice in a nation under transition: English language spread in Cambodia. New York, NY: Springer.

Coluzzi, P. (2009). The Italian linguistic landscape: The cases of Milan and Udine. International Journal of Multilingualism, 6(3), 298-312. doi: 10.1080/14790710902935930

Gorter, D. (2006). Further possibilities for linguistic landscape research. In D. Gorter (Ed.), Linguistic landscape: A new approach to multilingualism (pp. 81-89). Bristol, UK: Multilingual Matters.

Huebner, T. (2006). Bangkok's linguistic landscapes: Environmental print, codemixing, and language change. International Journal of Multilingualism, 3(1), 31-51.

Huebner, T. (2009). A framework for the linguistic analysis of linguistic landscape. In E. Shohamy \& D. Gorter (Eds.), Linguistic landscape: Expanding the scenery (pp. 70-87). New York, NY: Routledge.

Kasanga, L. A. (2012). Mapping the linguistic landscape of a commercial neighborhood in Central Phnom Penh. Journal of Multilingual and Multicultural Development, 33(6), 553-567.

Landry, R., \& Bourhis, R. Y. (1997). Linguistic landscape and ethno-linguistic vitality: An empirical study. Journal of Language and Social Psychology, 16, 23-49.

Leeman, J., \& Modan, G. (2010). Selling the city: Language, ethnicity and commodified space. In E. Shohamy, E. Ben-Rafael, \& M. Barni (Eds.), Linguistic landscape in the city (pp. 182198). Cornwall, UK: MPG Books Group.

Lou, J. J. (2012). Chinatown in Washington, DC: The bilingual landscape. World Englishes, 31(1), 34-47.

Lowell, C. O. (Producer). (2012, October 28). City of Lowell recognizes Cambodian town. Retrieved from http://archive.lowellma.gov/newsitems/4-15-2012-CambodiaTown/

Ly, M. (Producer). (2011, October 29). Lowell prepares for its own Cambodia Town. Retrieved from http://www.voacambodia.com/content/lowell-prepares-for-its-own-cambodia-town133820648/1355162.html

Needham, S., \& Quintiliani, K. (2010). Cambodian American secondary migration and community growth. In J. H. X. Lee (Ed.), Cambodian American Experiences: Histories, communities, cultures, and identities (pp. 64-75). Dubuque, IA: Kendall Hunt Publishing Company.

Sayer, P. (2010). Using the linguistic landscape as a pedagogical resource. ELT Journal, 64(2), 143-154. doi:10.1093/elt/ccp051

Silverman, D. (2006). Interpreting qualitative data (3rd ed.). Los Angeles, CA: SAGE.

Torkington, K. (2009). Exploring the linguistic landscape: The case of the golden triangle in the Algarve, Portugal. Paper presented at the The Lancaster University Postgraduate Conference in Linguistics \& Language Teaching. 


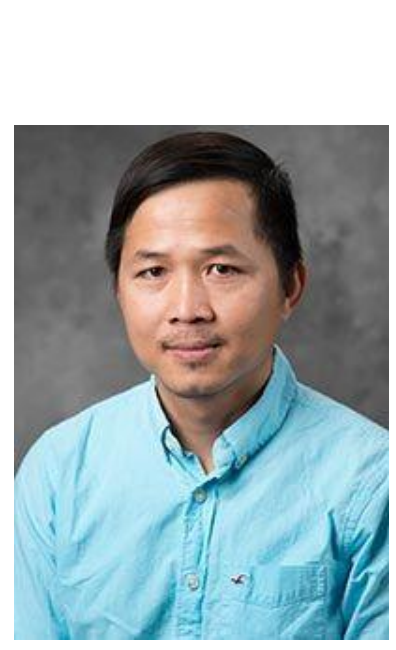

\begin{abstract}
About the Author
Virak Chan, Ph.D., is a Visiting Assistant Professor of Literacy and Language in the College of Education at Purdue University (West Lafayette, Indiana). He obtained his Ph.D. in Culture, Literacy, and Language at the University of Texas at San Antonio, Texas. He is from Cambodia and has extensive experience as a University Lecturer in training English teachers and as a coordinator of the M.A. TESOL program at the Institute of Foreign Languages of the Royal University of Phnom Penh, Cambodia. He has also taught various ESL methods courses both face-to-face and online in California, Texas, and Indiana. His research area focuses on language and education policies and practices for linguistically and culturally diverse students. He is also
\end{abstract} researching teacher education, linguistic landscape, teaching writing and curriculum development. 


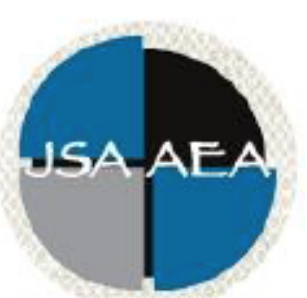

Vol.13 Iss.1 (2018)

\section{Journal of Southeast Asian American Education and Advancement}

\author{
Editor \\ Dr. Wayne E. Wright \\ Purdue University \\ Associate Editors \\ Dr. Chhany Sak-Humphry \\ University of Hawaii at Manoa \\ Dr. Phitsamay Sychitkokhong Uy \\ University of Massachusetts, Lowell \\ Book Review Editor \\ Dr. Vichet Chhuon \\ University of Minnesota \\ Creative Works Editor \\ Bryan Thao Worra \\ Lao Assistance Center \\ Journal Manager \\ Fang Gao \\ Purdue University
}

Editorial Review Board

\author{
Dr. Steve Arounsack \\ California State University, Stanislaus \\ Dr. Sovicheth Boun \\ Salem State University \\ Dr. Virak Chan \\ Purdue University \\ Dr. Loan Dao \\ University of Massachusetts Boston
}

\author{
Dr. Carl L. Bankston III \\ Tulane University \\ Dr. Phala Chea \\ Lowell Public Schools \\ Dr. George Chigas \\ University of Massachusetts, Lowell \\ Dr. Hien Duc Do \\ San Jose State University
}


Dr. Changming Duan

University of Missouri-Kansas City

Dr. Sothy Eng

Lehigh University

Dr. Vincent K. Her

University of Wisconsin, Eau Claire

Dr. Peter Nien-Chu Kiang

University of Massachusetts, Boston

Dr. Kevin K. Kumashiro

University of Illinois, Chicago

Dr. Ha Lam

Eastern Mennonite University

Dr. Jonathan H. X. Lee

San Francisco State University

Dr. Monirith Ly

Royal University of Phnom Penh

Dr. Bic Ngo

University of Minnesota

Dr. Leakhena Nou

California State University, Long Beach

Dr. Mark Pfeifer

SUNY Institute of Technology

Dr. Loan T. Phan

University of New Hampshire

Dr. Karen Quintiliani

California State University, Long Beach

Dr. Angela Reyes

Hunter College

The City University of New York

Dr. Fay Shin

California State University, Long Beach

Dr. Christine Su

College of San Mateo

Dr. Alisia Tran

Arizona State University

Dr. Khatharya Um

University of California, Berkeley

Dr. Kim Tran

University of California, Los Angeles,

Glendale Community College

Dr. Molly Wiebie

The University of Texas at Austin
Dr. Sophal Ear

Occidental College

Dr. Jeremy Hein

University of Wisconsin, Eau Claire

Dr. Nancy H. Hornberger

University of Pennsylvania

Dr. Peter Tan Keo

New York University

Dr. Yvonne Kwan

San Jose State University

Dr. Ravy Lao

California State University, Los Angeles

Dr. Stacey Lee

University of Wisconsin, Madison

Dr. Sue Needham

California State University, Dominguez Hills

Dr. Max Niedzwiecki

Daylight Consulting Group

Dr. Clara Park

California State University, Northridge

Dr. Giang Pham

University of Massachusetts Amherst

Dr. Malaphone Phommasa

University of Clifornia Santa Barbara

Dr. Kalyani Rai

University of Wisconsin-Milwaukee

Dr. Cathy J. Schlund-Vials

University of Connecticut, Storrs

Dr. Nancy J. Smith-Hefner

Boston University

Dr. Yer J. Thao

Portland State University

Dr. Monica M. Trieu

Purdue University

Dr. Silvy Un

Saint Paul Public Schools

Dr. Linda Trinh Vo

University of California, Irvine

Dr. Yang Sao Xiong

The University of Wisconsin-Madison

Dr. Zha Blong Xiong

University of Minnesota 


\section{Doctoral Student Editorial Review Board}

\author{
Linh Dang \\ University of Rochester \\ My-Lan Huynh \\ California State University East Bay \\ Hoa Nha Nguyen \\ Boston College \\ Thien-Huong Ninh \\ University of Southern California \\ Krissyvan Truong \\ Claremont Graduate University \\ Melissa Vang \\ San Diego State University \\ Claremont Graduate University \\ Anna H. Yang \\ University of Georgia
}

\author{
Annie BichLoan Duong \\ San Joaquin County Office of Education \\ Dung Minh Mao \\ University of Minnesota \\ Khoi Nguyen \\ George Mason University \\ Linda Marie Pheng \\ University of Wisconsin-Madison \\ Mai Vang \\ University of Massachusetts Boston \\ Soua Xiong \\ San Diego State University \\ Claremont Graduate University
}

